
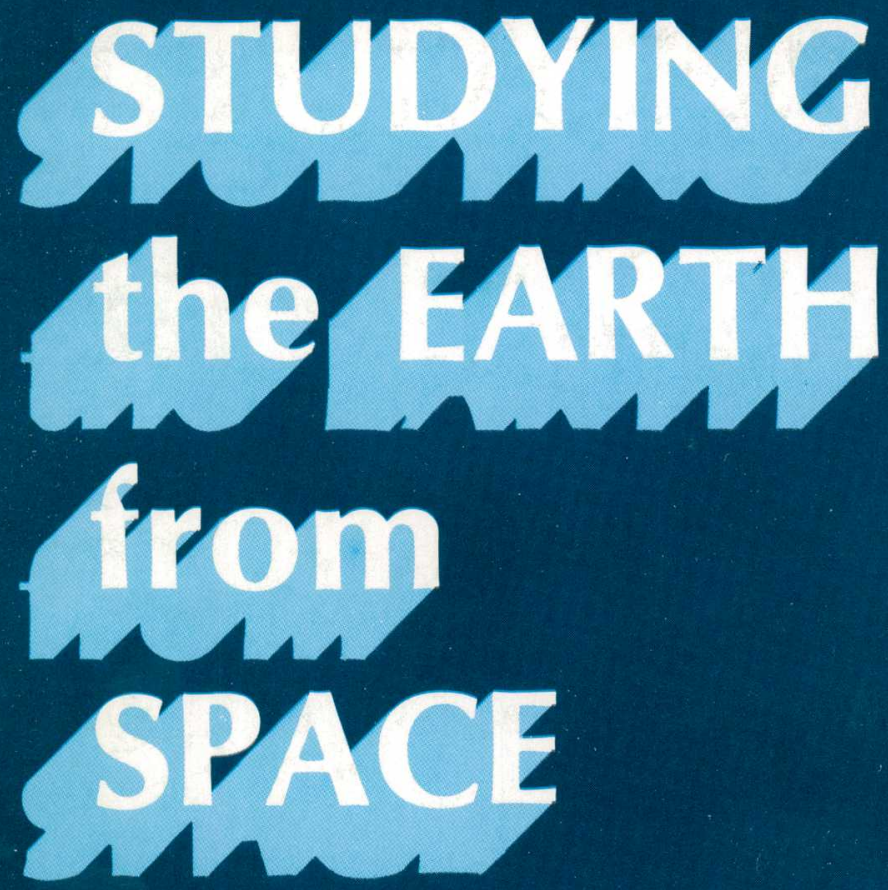


\section{THE TOOLS}

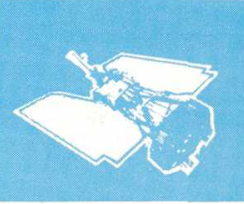

Within the technology of the space age lies a key to increased knowledge about resources of the Earth. This key is remote sensingdetecting the nature of an object without actually touching it. An early form, and still the most useful form, of remote sensing is photography. In this case the scene is recorded as man sees it, on film sensitive to electromagnetic energy called visible energy. Electromagnetic energy travels as a wave, with various wavelengths. Names applied to progressively longer wavelength forms of energy from the visible are infrared, microwave, and radio short wave and long wave. Progressively shorter wavelength forms from the visible are ultraviolet, $x$-ray, and gamma ray. Instrument systems exist that can produce photographs and images (pictures by instruments other than photographic cameras) of electromagnetic energy distributions in each part of the electromagnetic spectrum. These instruments include photographic cameras, scanning radiometers, and radars.

Each part of the electromagnetic energy spectrum is especially suitable for providing information about some aspect of our world. Black and white aerial photography, used stereoscopically, can provide accurate measurements of size, shape, and location of objects. It is routinely used for the preparation of topographic maps, to examine rangeland, agricultural crops, and timber stands, to assess storm damage, to select sites for engineering works, to map structural geologic features such as faults and mountain folds, and to explore for minerals.

Color, mainly because of the addition of hue, increases the usefulness of photography for the identification of rock and soil types, vegetation, surface water condition, and materials in houses, roads, and other objects on the Earth's surface.

Improving standard maps with space photography.

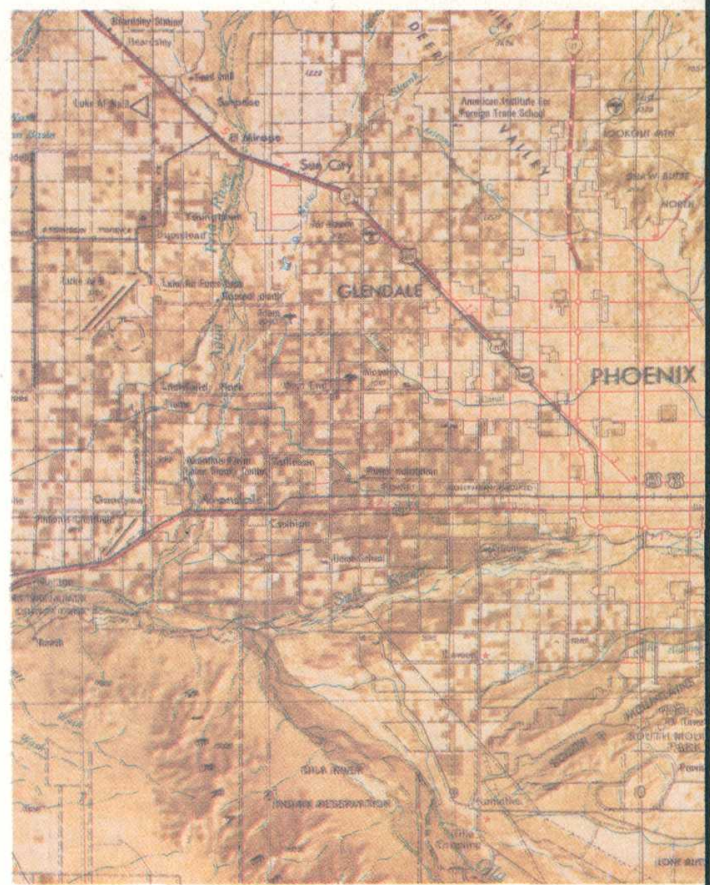


Color infrared photography, which records some information that man cannot see, but that can still be recorded on film, records in colors that are not true to nature in order to enhance recognition of vegetation and vegetation conditions. The film was developed especially for camouflage detection during World War II. Leaves of healthy plants generally have high reflectance in the infrared and are recorded as red to contrast it with dead vegetation which appears green or blue. Variations in red may indicate the presence of differing species or presence of diseased or dead plants, because the amount of reflectance varies with leaf structure and plant vitality. It is also possible to obtain indirectly, information on the availability of water and the physical character and mineral constituents of soils from the variations in vegetation response because these factors significantly affect the distribution and vitality of vegetation.

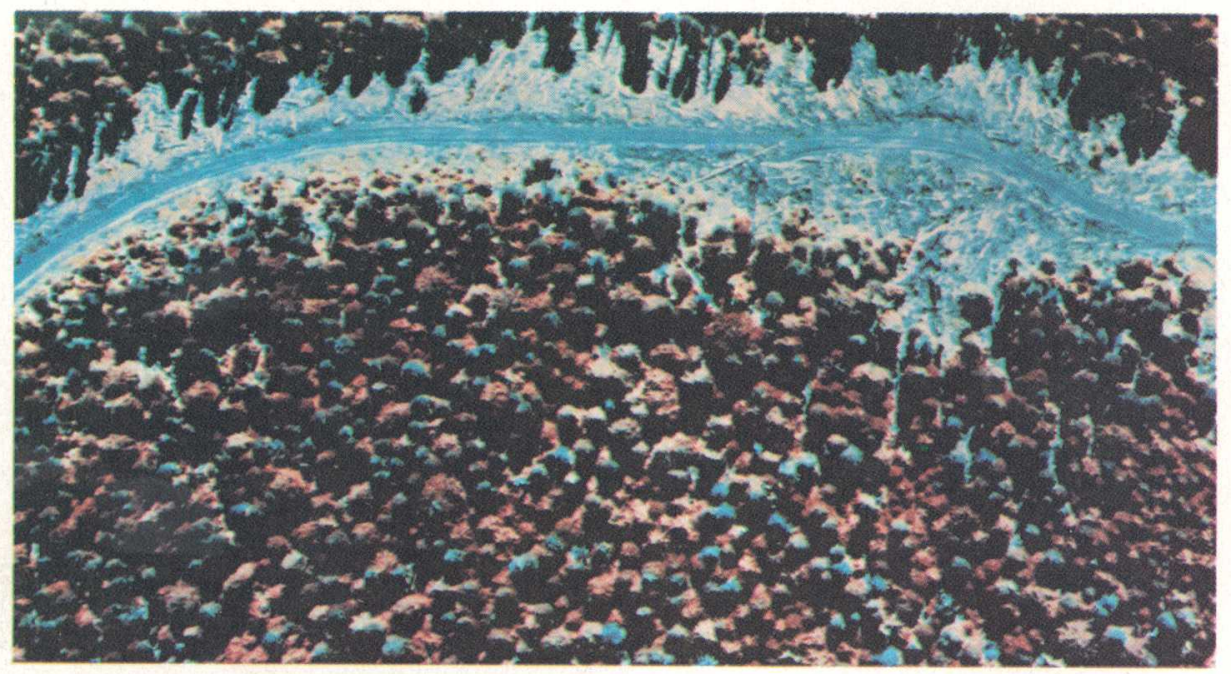

Insect-infested timbers in Oregon appear blue on this aerial color infrared picture. Healthy trees appear red or pink.

Beyond the visible and near infrared, special detectors, other than the eye-like optical lenses of photographic cameras, must be used. The technique is to convert the electromagnetic energy to electrical energy. The electrical energy may then either activate a light source such as a cathode ray tube (similar to a TV picture tube) to produce an image or may be recorded directly on magnetic tape (similar to a tape recorder). Some of the instruments (radiometers) measure energy emitted from an object and in fact are recording radiant temperature differences at or near the surface in the far infrared part of the spectrum, and other instruments (including radars) measure reflected or emitted radio waves in the microwave and longer wavelengths of the spectrum. Both radiometers and radars scan a scene line by line and are therefore called scanners. Because sunlight plays no direct role in the observations made by these instruments, they may be used day or night and some systems can observe through clouds. 
The measurement of temperature differences and mapping their distribution can reveal volcanic activity, underground fires, forest fires normally obscured by smoke, animals, and heated buildings. It can, by revealing surface temperature distributions in water, aid in the discovery of springs discharging into lakes, rivers, and oceans. It can provide information on moisture conditions near the ground surface because variations in moisture affect surface temperature. $t$ nd it can indirectly provide information on the physical properties of soils and rocks because retention and loss of heat are primarily determined by these characteristics.

Radar records the reflection of a radio signal transmitted from the radar itself to the ground. The signals are affected by the roughness and attitude of the reflecting surface and the electrical properties of materials. The absence of detail, the uniformity of illumination, and the continuous coverage of large areas enhance subtle details often obscured in photographs. Radar has been particularly useful in revealing geological structures.

There are many other remote sensors, but these are the more common ones. The proper selection of sensors, based on what is to be discriminated and what its spectral response will be compared to its surroundings, has been and continues to be the subject of long and difficult investigations. Results show that in the visible and infrared many discriminations are possible by using more than one picture of the same scene with each picture recording a different wavelength band. This is called multispectral photography or imagery. This system has been used in both airplanes and satellites. Power limitations have thus far prevented the use of radar from satellites.

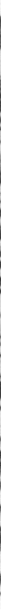

One tool for developing synoptic terrain maps is airborne, side-looking radar which sharply defines valleys, slopes, ridges, and other topographic features. This radar image of a portion of the San Francisco Peninsula, is remarkable for its clear definition of the San Andreas fault zone and related faults. Note how water surfaces reflect radar waves away from the receiver and appear black. Near-surface moisture in soils generally appears dark gray. Cultural features such as buildings, roads, and power lines, reflect large quantities of energy back to the receiver and thus appear white. 


\section{INTERPRETATION OF SPACE DATA}

In March 1969, the crew of the Apollo 9 spacecraft took a series of multispectral photographs covering the southern part of the United States. This was the Multispectral Terrain Photography Experiment conducted in response to a request from the Departments of the Interior and Agriculture. These and other investigations have shown that space data can be applied in resources planning, management, conservation, and preservation of food, minerals, water, land, and human resources, as well as in the design of engineering works. Satellite-collected data may be applied in the fields of cartography, geology, geography, hydrology, marine resources, and land management, and specifically to studies such as major geologic structural features, assessing hydrologic problems, determining the condition of rangeland, mapping land use for urban planning, studying erosion and change along coastlines and major streams, and inventorying land use and landforms in the entire United States.

The many purposes served by space photography, include: synoptic land-use mapping, recognition and mapping of dynamic hydrologic processes as seen in the Salton Sea swirl, and landform and geologic structural mapping.

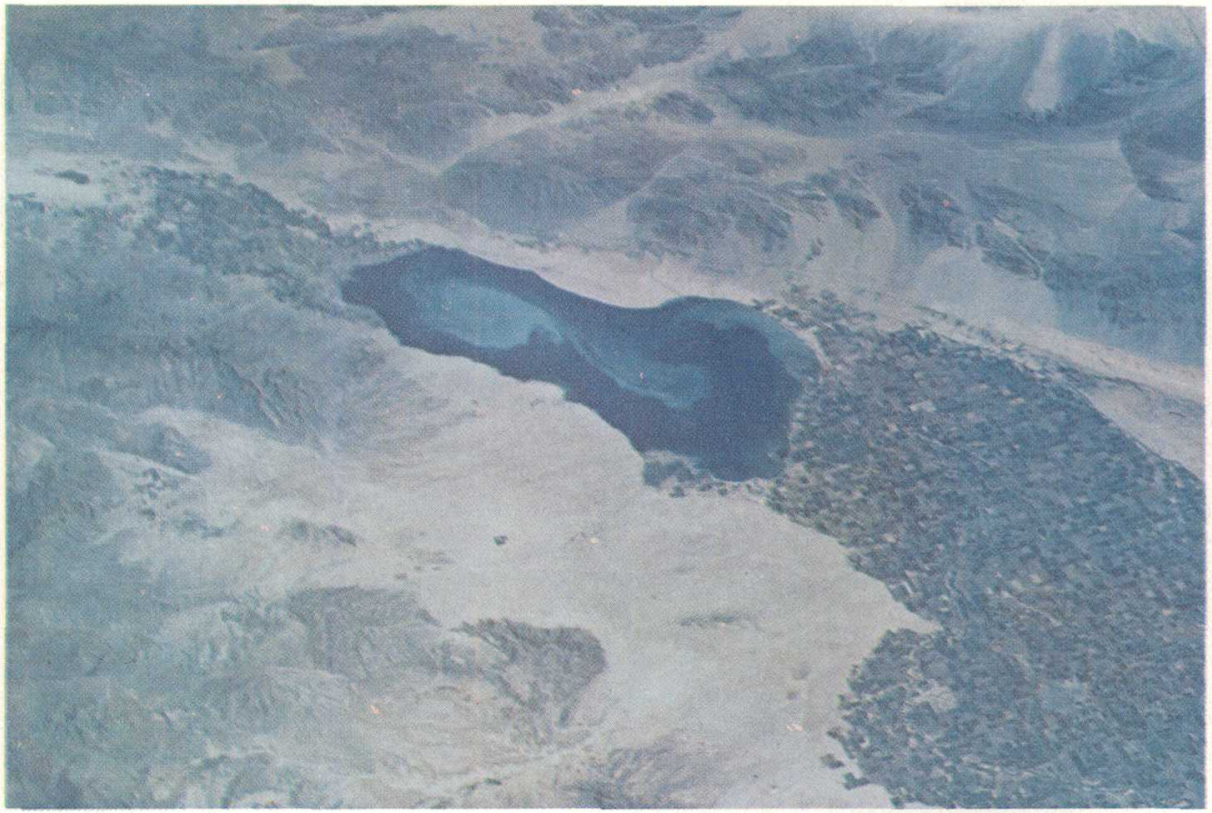




\section{CARTOGRAPHIC APPLICATIONS}

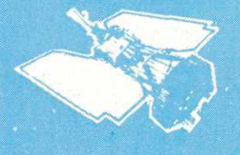

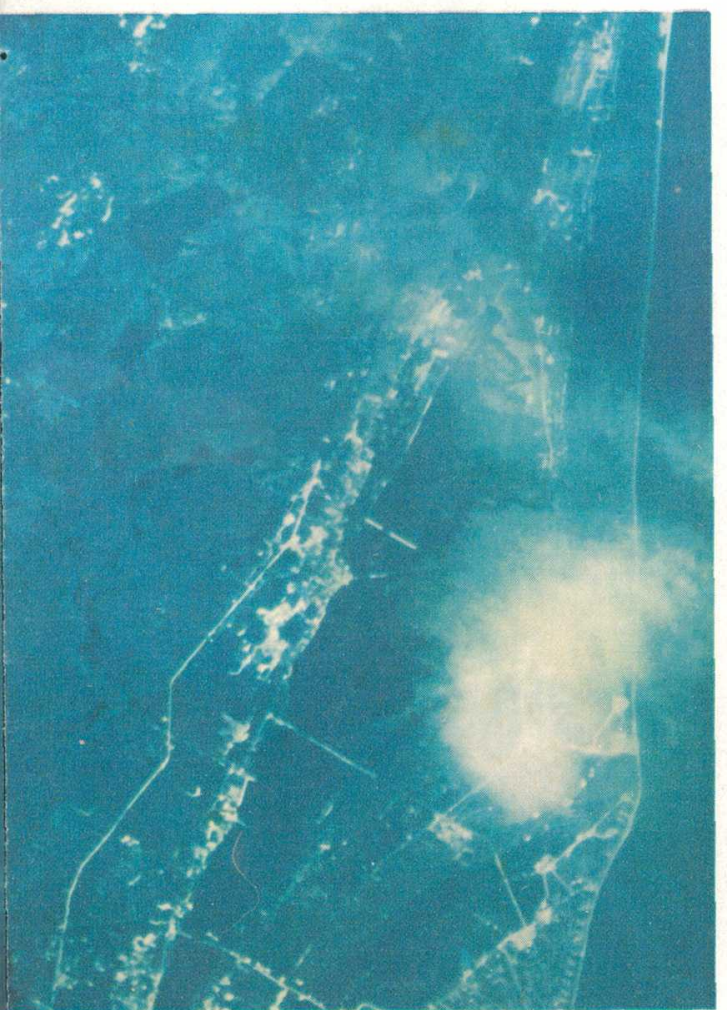

New construction can be identified on this CEMINI VII photograph of Cape Kennedy taken in 1965 (above), when compared to the latest 1:250,000 scale map available at the time (right).

Space-acquired data about the Earth's surface afford several advantages to mapmakers. Photographic data from satellites in a circular, sun-synchronous orbit will provide a basis for mapping and charting that will be of uniform reliability. Even more important,
Maps are the basic tools for resources studies. They are essential in planning engineering works, geologic and hydrologic research, mineral investigations, flood controls, soil conservation, reforestation, and land management. In short, maps depict the face of the Earth-showing in measurable form its terrain, bodies of water, vegetation, and the works of man.

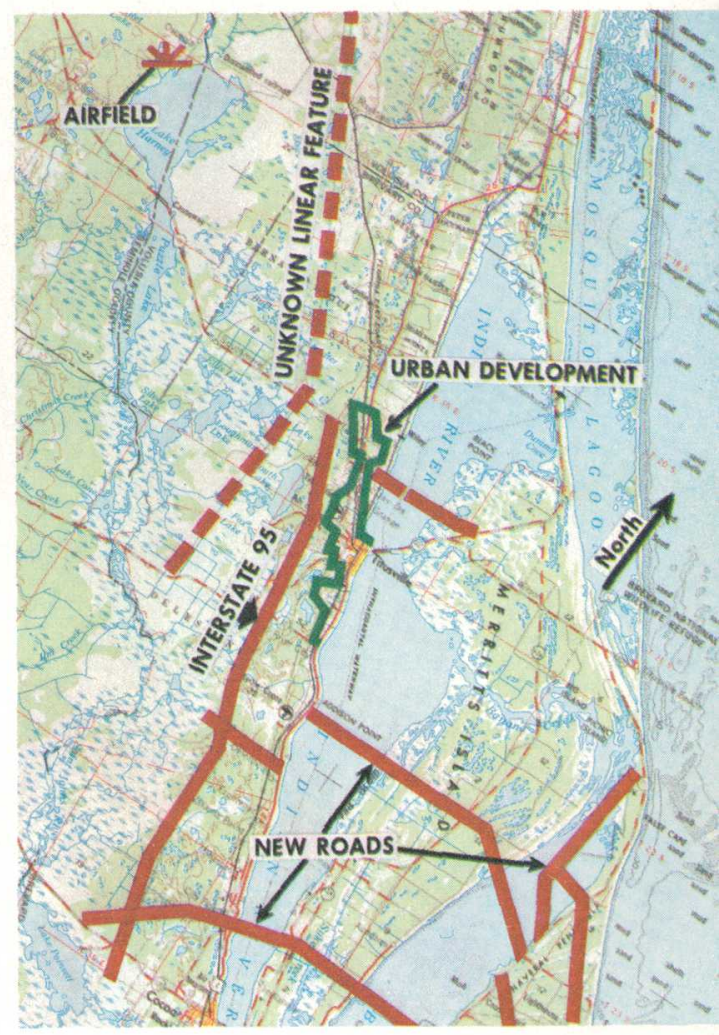



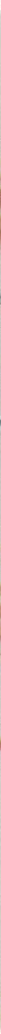

Automatic mapping from satellite photography is being developed to increase the currency of data interpretation. This APOLLO 9 photograph of the Phoenix, Arizona area was processed to extract the reflective vegetation photographed as red on the color infrared film, thus automatically creating a vegetation map.

pictures taken from orbital altitudes with relatively narrow-angle viewing systems are nearly orthographic, that is the distortions are at a minimum.

The value of using orbital-height photographs in cartographic programs has already been demonstrated. The Gemini VII flight was particularly successful in obtaining good photographs from a height of 165 miles above the Cape Kennedy area. Many major changes that occurred between the time of the mapping and the time of the photography can be identified, indicating that orbital-height photographs can be used to bring certain maps up-to-date.

At present, vast areas of the world are without meaningful map coverage, and certain remote areas, such as Antarctica, are largely unsurveyed. Image data obtained from orbiting satellites have the potential of greatly increasing the opportunities for acquisition of data, and increasing the efficiency and reducing the time required for many mapping operations. 


\section{GEOLOGIC APPLICATIONS}

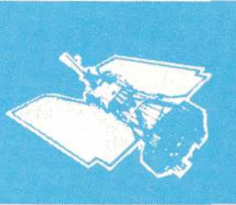

The study of natural resources and the appraisal of the probability of natural disaster, such as landslides, earthquakes, and volcanic eruptions, and their possible effects on man, are major interests of the Department of the Interior. For more than 20 years, photogeology has been an established technique in support of these studies, particularly useful and economical in difficult terrain or in inaccessible areas. Space photography increases the potential of this tool, especially if supplemented by other remotesensor data, such as infrared and radar imagery.

Satellite photography has been useful for identification of geologic structure of regional extent because the single view provided by orbital height is easier to interpret than many aerial photographs taken with differing illumination. For example, identification of a large circular structure was made for the first time on an Apollo 9 photograph of eastern Arizona that warranted further investigation for mineral and water resources.

The large, circular crater (upper right), 30 miles in diameter, has been interpreted by some as a meteor impact area and by others as the result of an igneous plug pushing up from great depths of the earth as the result of structural forces. The bedrock shown in the space photograph (lower right), but not covered in the photomosaic, indicates that this region has been structurally deformed. Note how the even illumination of the space photograph increases the clarity and ease of interpretation.

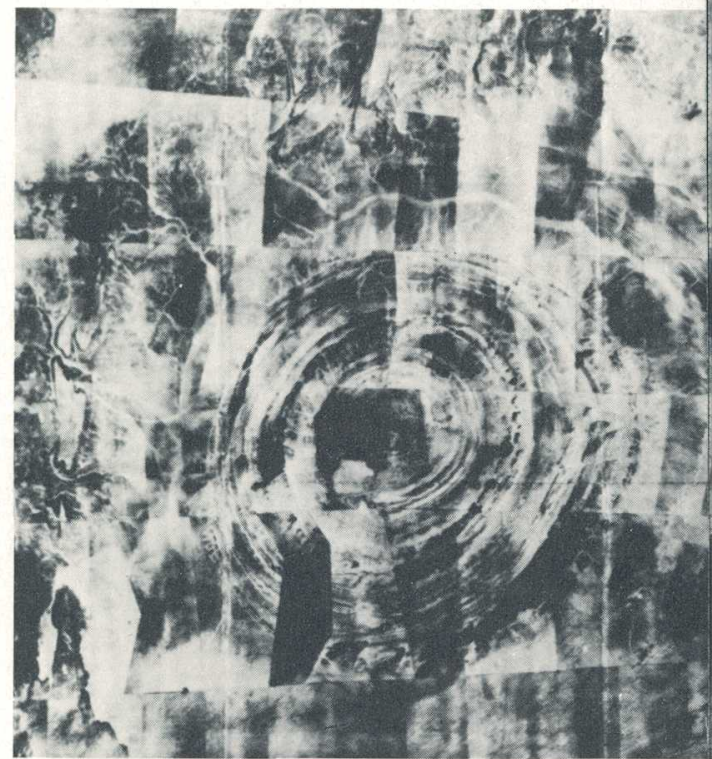

ER RICHAT, SAHARA DESERT,MAURITANIA 


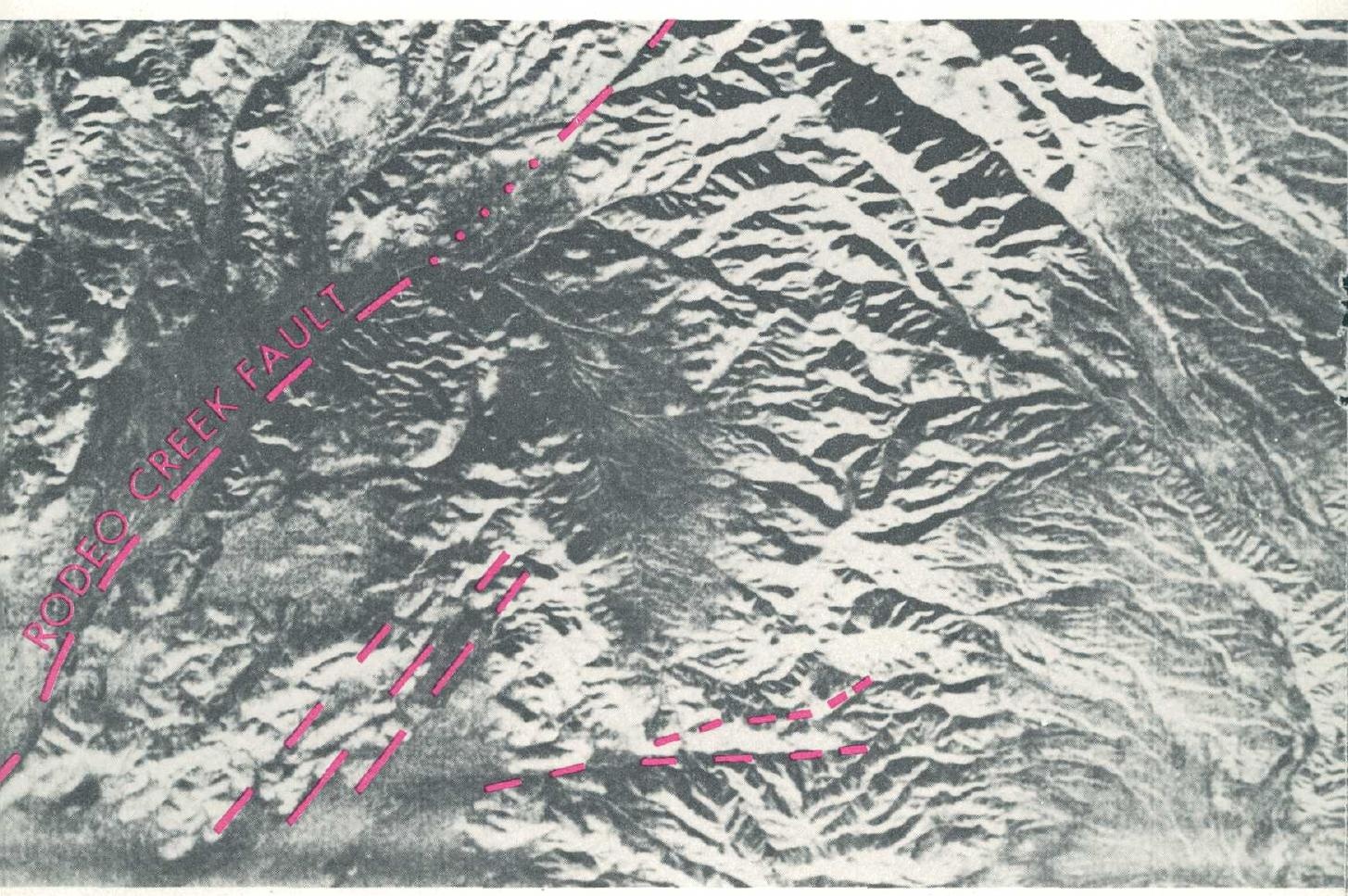

Faults not previously recognized during field mapping have been identified on airborne radar imagery which is useful in revealing geological structures.

Radar imagery, on a more local scale, has also been used to identify geologic structure of possible economic significance. Faults, sometimes important in the localization of mineral-bearing fluids that form ore deposits, and broad gentle folds, that commonly serve as reservoirs for petroleum, are particularly well defined on radar imagery. Interpretation of some imagery taken over a working mining area in Nevada revealed faults not detected by earlier field mapping or on conventional aerial photographs and led to renewed exploration in the mining area.

Thermal infrared sensing techniques are contributing to our basic knowledge of the Earth. For example, studies of the distribution of thermal anomalies in Iceland, principally by means of airborne infrared surveys, but also from Nimbus satellites, have provided information on the temperature characteristics of terrain and water surfaces, and in the studies of volcanoes. This knowledge may eventually be used in searching for geothermal power sources. In a practical application that affects our daily lives now, airborne thermal infrared imagery has been used to locate underground coal fires. Locating subterranean fires has permitted intelligent planning to control the fires and evacuate endangered people. 


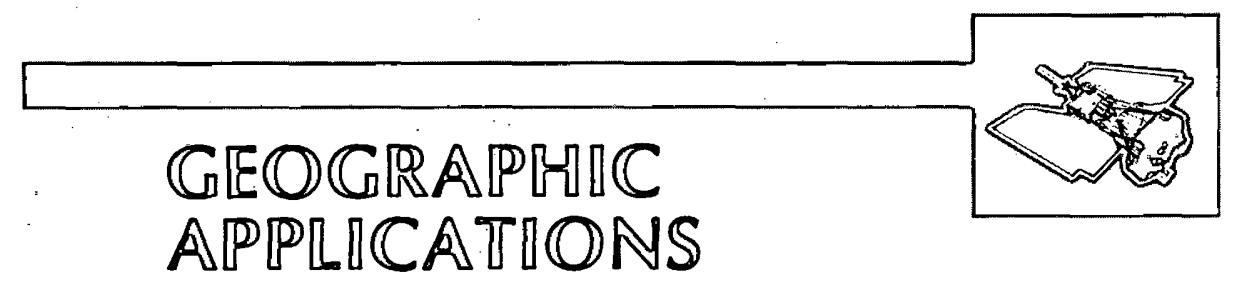

Fundamentally, geography deals with the location and arrangement of such factors as environmental conditions, Earth features, resources, population, and a wide range of other natural and cultural phenomena, in relation to human activities. When the objective is to determine changes in human use of the Earth over large areas, data acquired from space are often more useful than larger scale data obtained from conventional aircraft or from ground surveys. Satellite observations can provide a great reservoir of geographic information in a complete environmental context: single-picture coverage of broad areas for planning; repetitive coverage for the analysis of urban growth, functional changes, crops, and transportation linkages; emergency coverage of disaster effects; and scientific data for research and educational purposes. Space-acquired data are also comparable, up-to-date, and at small scales, close to those traditionally used for special subject maps and for analysis of weather conditions, land use, and census results.

Data from traditional sources were supplemented by high-altitude and satellite photography in a study of the economic potentials and environmental problems of southern Mississippi prepared for NASA in February 1970. Extensive use was made of remotely sensed data in preparing this comprehensive study of possible new uses for the NASA Mississippi Test Facility built to test large rocket engines. The study formed the basis for recommendations and plans, and successfully demonstrated the value of a variety of remote sensor data, each making a unique contribution, to a comprehensive analysis of environmental factors. This technique of fully integrated analyses is being applied to other selected regions, leading to production of maps or computerized data banks that will relate environmental conditions, human activities, and the probable effects of trends or changes to policy decisions.

Multispectral aerial photography of 26 selected cities, mostly taken at the time of the 1970 census, is being analyzed for preparation of data bases and maps of urban change. The various wavelength bands are used singly and in combination to map water features, improved open space, unimproved open space, and several other categories of land use. These maps will be comparable with census data and with multispectral photography to be flown in 1972 and analyzed in the same manner, thus providing planners with an atlas of the type and rate of urban change. 


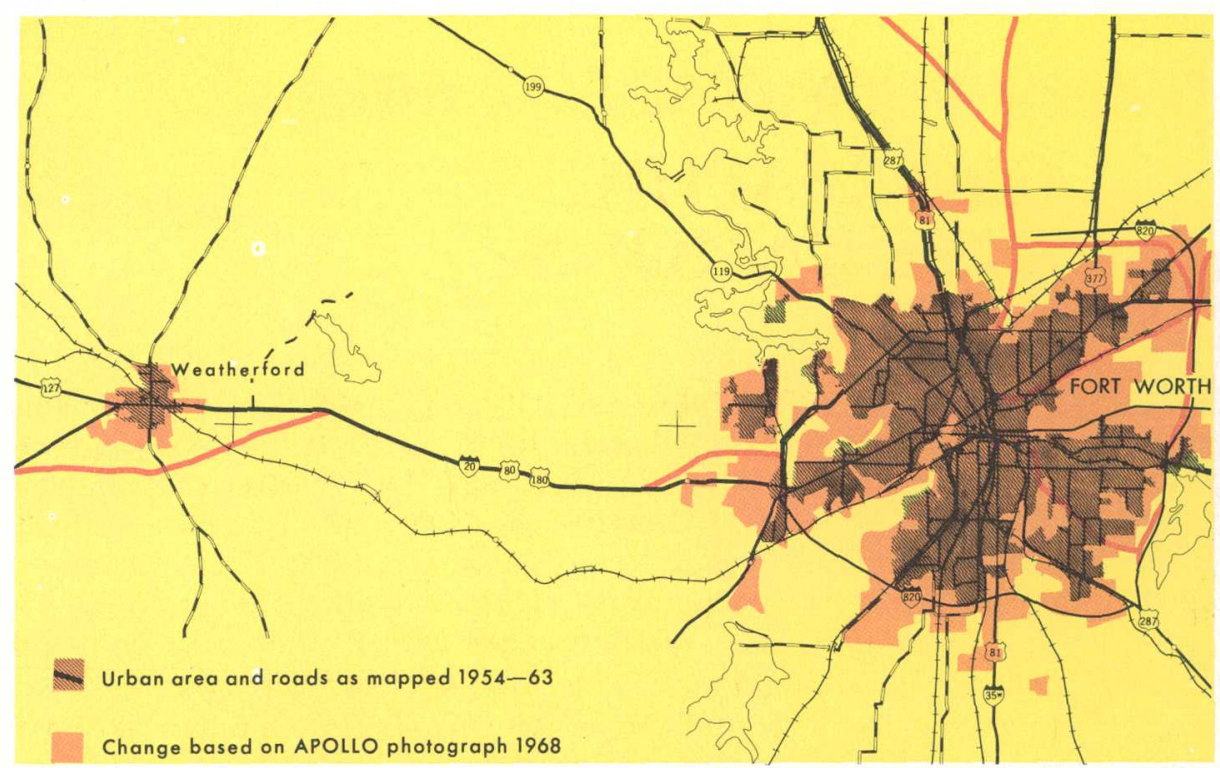

The extent of urban growth in 5 years is revealed by comparing the area mapped as urban in 1963 (at top), and as interpreted from an APOLLO 6 orbital photograph (at bottom) taken in 1968. This is an example of the utility of repetitive viewing, from orbital height; for measuring changes in phenomena.

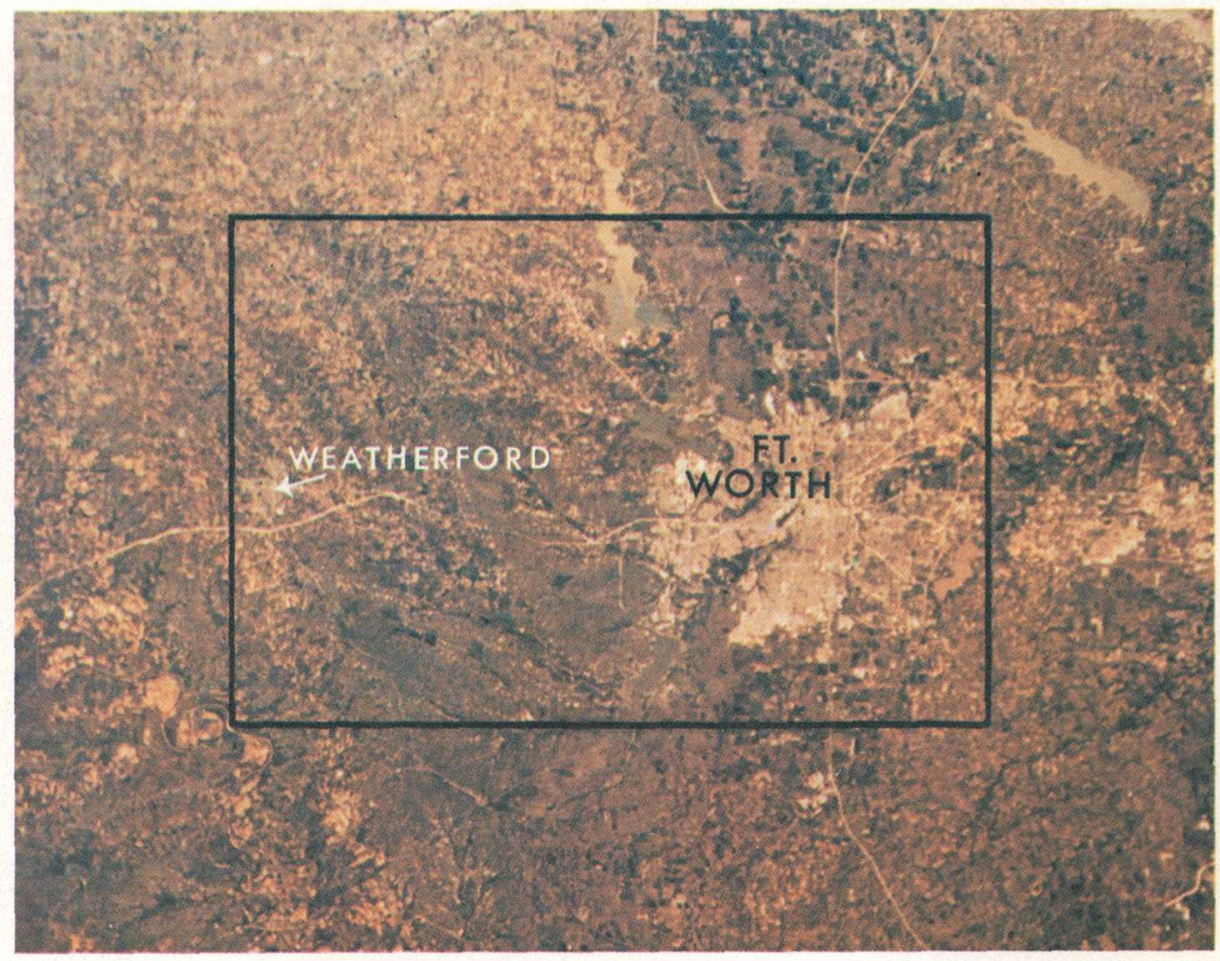




\section{HYDROLOGIC APPLICATIONS}

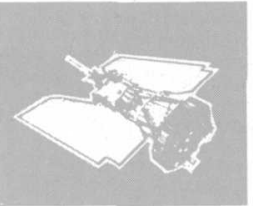

Important water resources planning and management information can be obtained from Earth-orbiting satellites as has been demonstrated through use of aircraft and satellite-acquired data. A perspective from space adds an areal dimension to conventional hydrologic data collected at point stations. Approximately 10,000 continuous waterstage recorders on streams, plus several times that number of ground-water wells, waterquality monitors, and short-term data collection stations are operated by the Geological Survey. The data from space will provide information between the station points for synoptic interpretation, while the point data will provide the needed calibration for the space data. Synoptic information will be available on drainage basin characteristics, hydrologic controls, vegetative indicators of hydrologic conditions, hydrodynamics, lake processes, pollution dynamics, and distribution of snow and ice.

The investigations of hydrologic engineering problems can be significantly advanced by use of specific remote-sensor data. For example, infrared instruments that record the thermal radiation from land and water surfaces were flown in an aircraft over the coastline of Hawaii, where many underground springs discharge fresh ground water into the ocean. The light and dark contrasts of the resulting images showed the cool fresh

Dark streaks on this aerial infrared image of Hilo, Hawaii, represent the discharge of $\mathrm{cool}$, fresh ground water into the warmer salt water of the ocean.

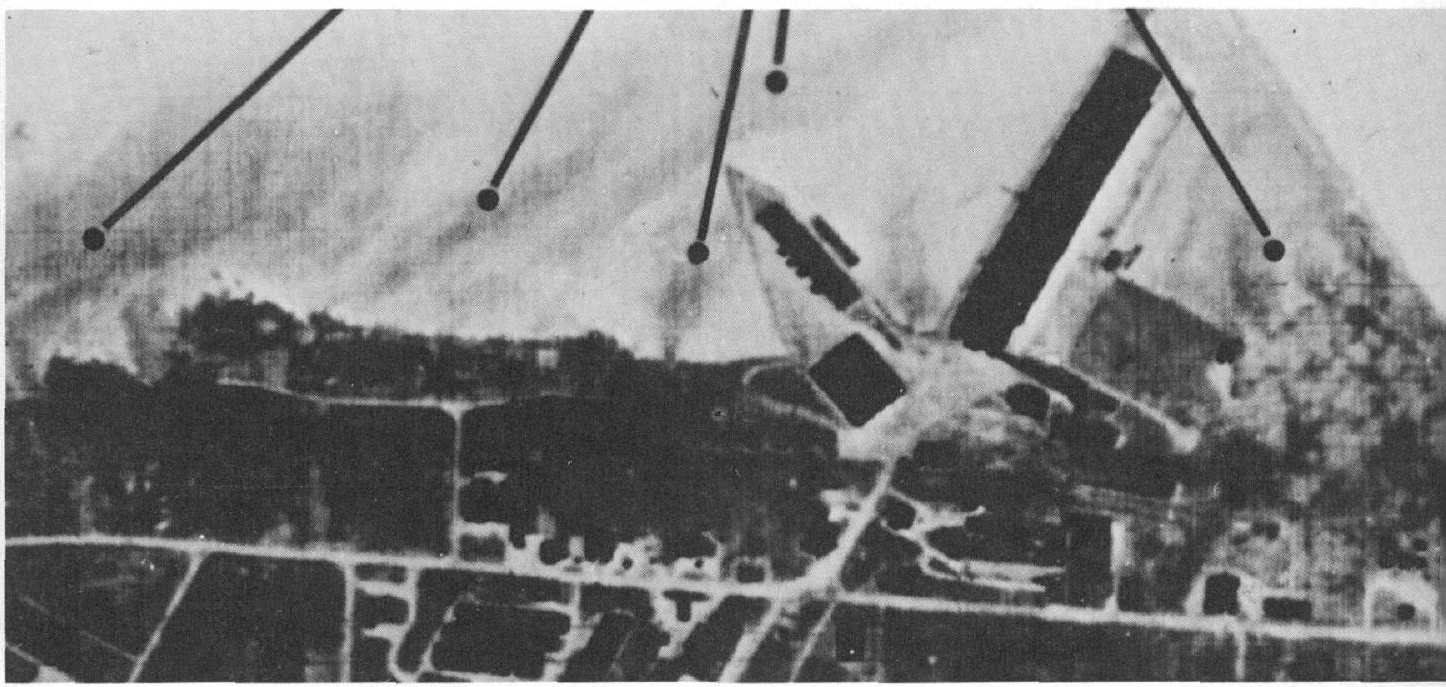


water as it entered the ocean and mixed with the warm salt water. Fresh water is a precious commodity in Hawaii. The location of such discharge points together with geologic information may guide the driller to fresh ground-water producing areas.

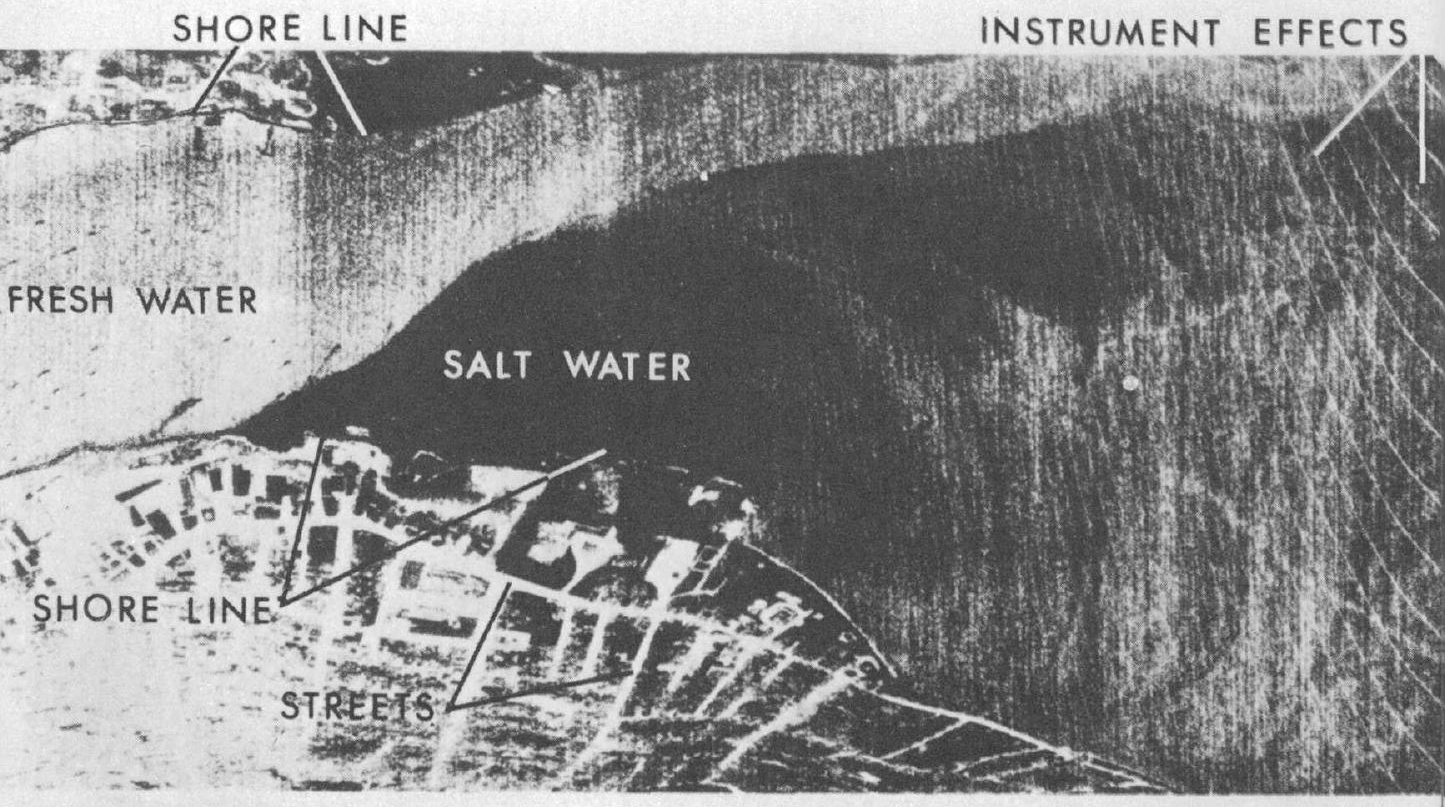

Infrared imagery, taken from an aircraft, shows the salt-water wedge in the estuary of the Merrimac River, Massachusetts, at flood tide because its temperature was different from the fresh river water.

Knowing the shape, size, and position of salt water as it intrudes into fresh-water streams is important for many reasons, but particularly for the protection of municipal water supplies. The conventional method of determining this intrusion is to sample the water, measure its chloride content, plot the sample on a map, and contour the position and shape of the salt water. In contrast to this method, the salt water in an estuary in Massachusetts was readily defined by infrared imagery because the temperature of the salty ocean water differed from that of the fresh river water.

Water pollution and the concentration of chemical and biological constituents of water are also commonly measured by sampling procedures or by continuously recording monitors. However, infrared color photographs enhance many of the contrasts on the surface of water bodies and aid the analysis because streaks produced by floating algae, foam, and other materials, as well as the wave pattern, can be detected and mapped. When these photographs are taken repeatedly, it is possible to study the dynamics of pollution, that is the rate at which pollutants move and also their distribution and dispersion within the water body. 
Infrared imagery, because of its particular ability to distinguish living vegetation, has also been used in the southwestern United States to monitor the growth and spread of water-loving plants that grow in the beds of intermittent streams and along watercourses. These plants use much of the limited water supply to no economic purpose and their effective control is important in water-resource management and planning.

The wetlands along the Georgia coast are recognizable on the color infrared APOLLO 9 photography. The marsh vegetation was not viable in March when the picture was taken and therefore appeared blue on the color infrared image. This also contrasts with the dry coastal beaches.

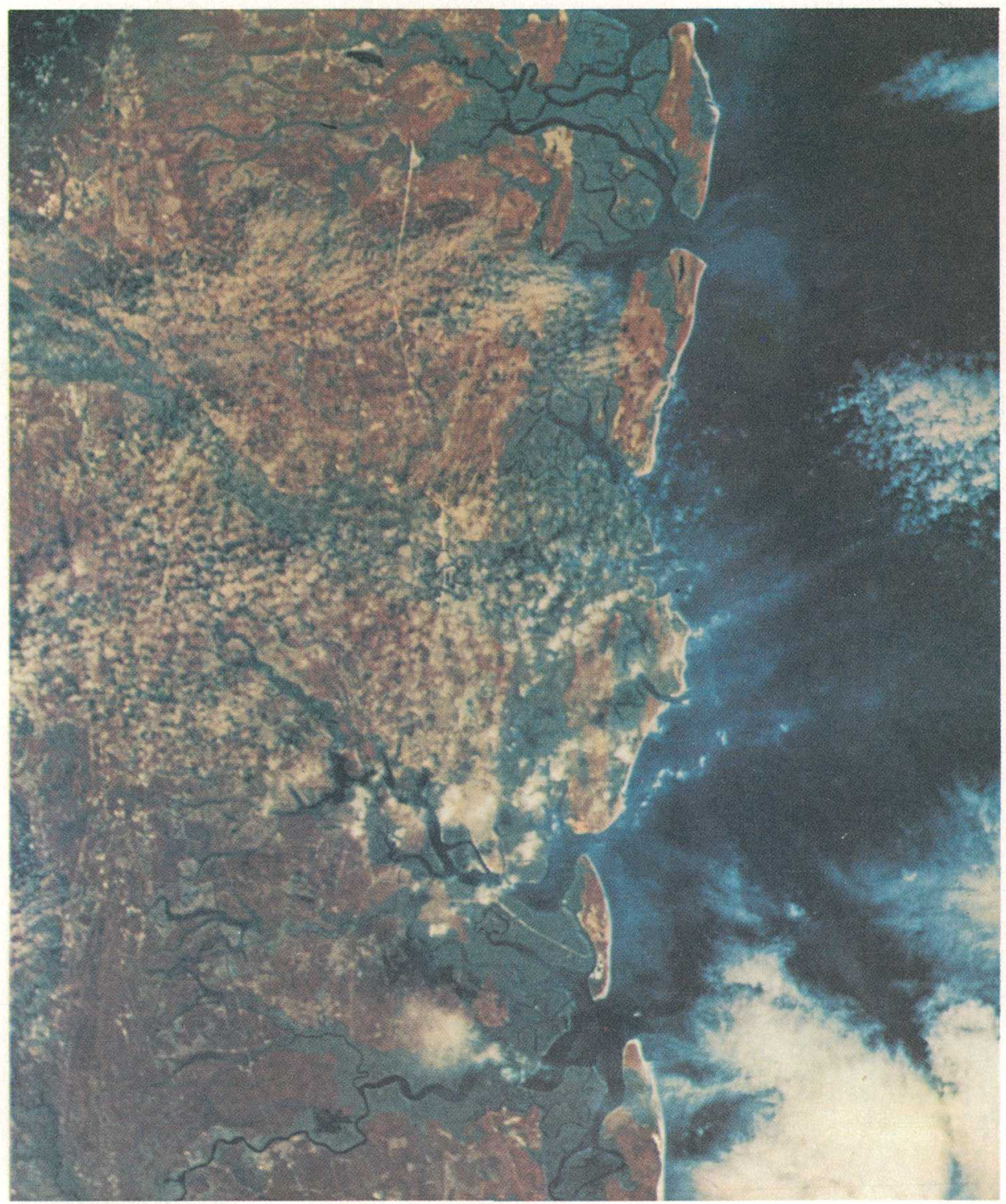




\section{MARINE APPLICATIONS}

Approximately 70 percent of the Earth's surface is covered by water, much of it not practically accessible for broad surveillance by conventional methods. Remote sensors, and especially remote sensors in spacecraft, offer new opportunities to learn about the oceans and their resource potential. The Department's interest is concentrated in the nearshore environment. Investigations concern what is there and how it changes, including surface temperatures, current patterns, types of waves, underwater topography, marine biology, mineralization, and coastal processes. In pursuit of this knowledge, repetitive photographs can be used to provide information on direction and rate of movement, and relative quantity of suspended matter, which in turn can be translated into prediction of change in coastal morphology and current patterns. Studies of Nimbus infrared imagery have also shown the feasibility of observing differences in water temperatures from satellites and relating temperature distributions to current patterns.

The effect of oil spills has accentuated the need for systems to previde early warning of accidents and monitoring subsequent efforts at control. The most success has been in the area of monitoring control and clean up efforts by the use of ultraviolet and color photography, and thermal infrared imagery which can record the temperature difference between newly released oil and ocean water. Eventually the oil temperature moderates to that of the ocean water and this technique is no longer effective.

Airborne monitoring of the oil slick at Santa Barbara, using three different wavelength bands, provided information on: source of oil (thermal infrared), distribution of oil (ultraviolet), and identification of kelp (solar infrared), more easily than by conventional means.

\section{THERMAL INFRARED}

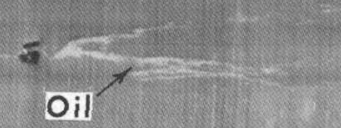

\section{ULTRAVIOLET}

\section{Oil Slick}

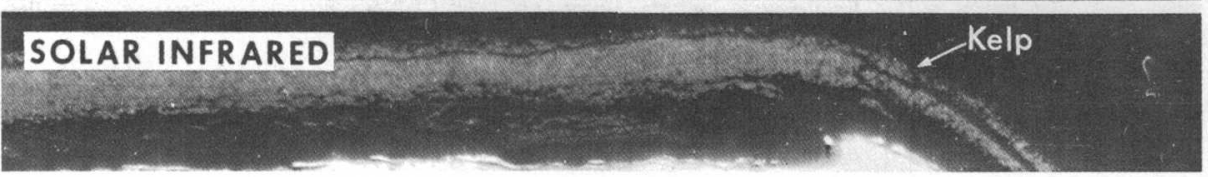




\section{LAND MANAGEMENT APPLICATIONS}

Public lands, national parks, and national forests include 175 million acres primarily in the western United States and 348 million acres in Alaska. Beyond their value as a resources base for the future, these public lands yield a substantial income to the Nation from oil, gas, forest products, grazing and recreation fees. Moreover, about 7 million head of livestock and nearly 3 million big-game animals depend on these lands for all or part of their year-long needs.

Space photography, particularly color infrared, has proved especially useful for the evaluation of distribution, health, and vigor of vegetation, the extent and relative depth of snow cover, and the relative moisture content of soils. The use of frequent repetitive coverage will allow for evaluation of change, a vital element that will give the land manager an immediate reading on the effects of his management practices, such as: Is there too much livestock grazing or can more livestock be supported on a particular range? Will the winter snow provide a year-long supply of water? And is a forest endangered by disease or has a disease been controlled?

Multispectral imagery is being used to study an area of potholes in Minnesota and the Dakotas. The multispectral imagery provides information on the surface area, depth, and other characteristics of the pothole lakes and the associated vegetation. The potholes are a breeding ground for ducks, and there is a known relationship between the condition of the breeding ground and the number of ducks produced. Sound game management requires that a yearly determination be made, preceding migration, of how many ducks should survive in order to establish the harvest or bag limit for hunters. This information is essential to provide maximum recreational benefits of hunting and yet assure the continued existence of the ducks themselves.

Proper maintenance and preservation of our national parks must be based on knowledge about their physical and biological components and the influences, particularly the adverse ones, which affect them, including such natural hazards as earthquakes or volcanic eruptions. Airborne thermal infrared surveys have been conducted of Kilauea volcano, which lies within the boundaries of the Hawaii National Park, and Yellowstone-National-Park- $+\mathrm{n}$-Hawaii; the-variation of temperature with time, location, and intensity suggests that repeated surveys may give timely 
warning of impending volcanic eruptions. In Yellowstone Park, studies have added to the basic knowledge of the distribution of heated waters in this thermally active area.
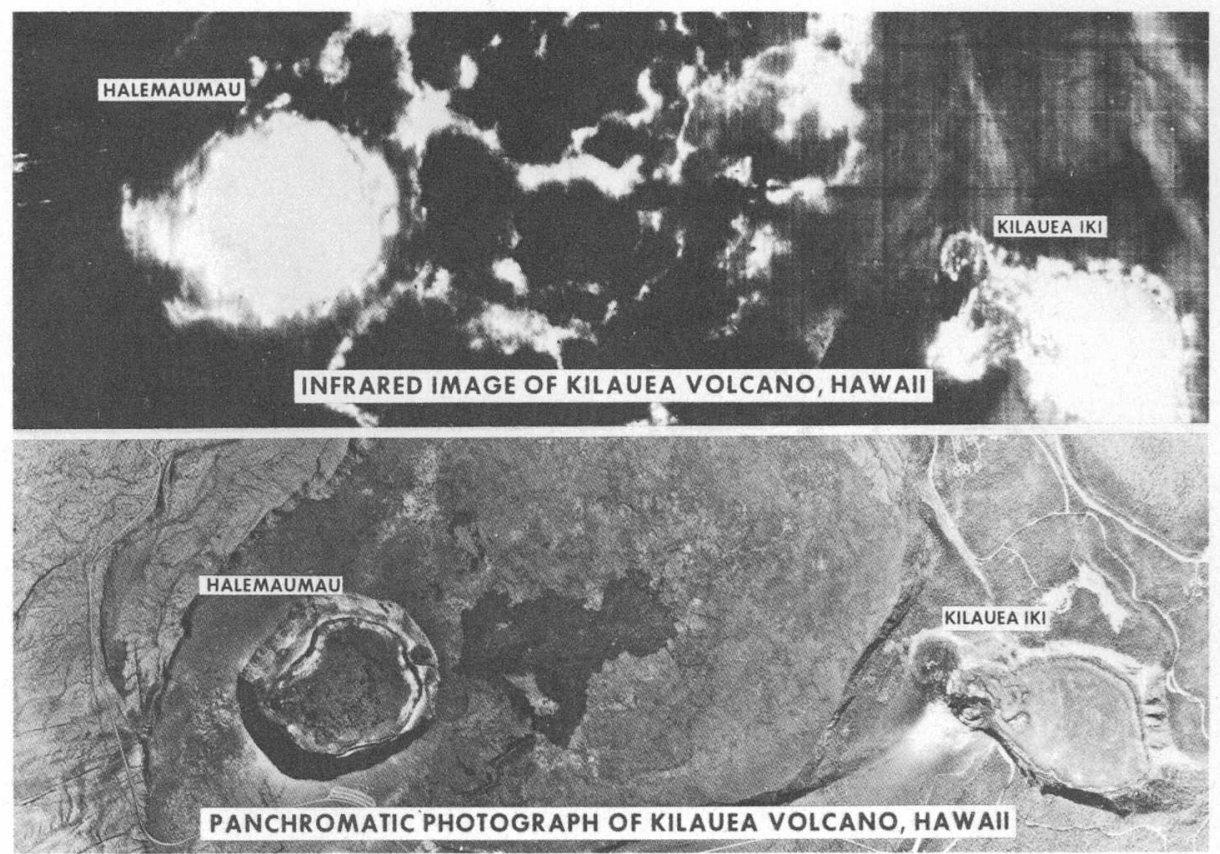

High-temperature areas in the crater and flanks of Kilauea Volcano, Hawaii are visible on the aerial infrared image, but cannot be identified on the conventional black-and-white photo of the same area.

\section{* * * * * * * * * * * * RESPONSE TO THE RESOURCE CHALLENGE}

Based on the potential of this technology and in response to the critical need for greater knowledge of the Earth and its resources, the Department of the Interior established the EROS (Earth Resources Observation Systems) program to gather and use remotely sensed data collected by satellite and aircraft of natural and manmade features on the Earth's surface. Thus far, the work of the program has been primarily with data collected by aircraft and has been focused on developing the ability to interpret remotely sensed data and on defining the proper roles of data collected at various altitudes. All this is leading to the use of data to be provided by ERTS (Earth Resources Technology Satellite) to be launched by NASA early in 1972. 
The initial (experimental) ERTS, with a 1-year lifetime, will be in a circular, near polar, Sun-synchronous orbit so that each point on the Earth's surface can be viewed repetitively (every 18 days) at the same time of day. The initial satellite's prime remote-sensing devices will be vidicon (TV-type) cameras operating in three separate wavelength bands (475-575 micrometers or blue-green, 580-680 micrometers or red, and 690-830 micrometers or near infrared), and an optical scanning system providing four wavelength bands of information in the visible and near infrared part of the spectrum which is expected to provide data for testing computer manipulation of data. Each image will be essentially orthographic, covering a square area 185 kilometers (100 nautical miles) on each side. Approximately 400 single-band vidicon images will cover the entire United States. It is expected that the data can be used for special subject mapping at scales of 1:250,000 or smaller. The satellite will also have the capability for relaying data from ground sensors (such as stream gages, vegetation and soil temperature recorders, and volcano seismometers and tiltmeters) to the collection center. This information will be used to correlate the photographic-type images with conditions on the ground.

The satellite will relay the collected data in electronic form through receiver stations on Earth where the signal will be converted to photographic-type images. These images will then be processed at a data center to be established in the vicinity of Sioux Falls, South Dakota. The data center will provide space-collected data to government users and to all other groups that can make beneficial use of it; prepare small-scale special subject maps from the space data for use by resource agencies; and will provide facilities for the use of some analytical and interpretive equipment, together with advice on methods of data use.

The use of remote sensing from aircraft and spacecraft is enabling the Department of the Interior to apply both the improved capability to study natural resources from data obtained from remote-sensing devices, and the broad regional coverage and frequent repetitive coverage provided by Earth-orbiting satellites to the development of a more effective resource information system. The EROS Program of the U.S. Department of the Interior is managed by the Geological Survey. Other participating organizations include: Alaskan Power Administration, Bonneville Power Administration, Bureau of Indian Affairs, Bureau of Land Management, Bureau of Mines, Bureau of Outdoor Recreation, Bureau of Reclamation, Bureau of Sports Fisheries and Wildlife, National Park Service, Office of Oil and Gas, Office of Saline Water, Office of Territorial Affairs, Office of Water Resources Research, Southeastern Power Administration, and Southwestern Power Administration.

(from material supplied by Priscilla W. Woll)

Revision of this booklet, illustrated with satellite photography and imagery, is in process. Users of this reprint are encouraged to look for the revision in the near future. The new issue will emphasize the use of ERTS and Skylab data. 
As the Nation's principal conservation agency, the Department of the Interior has basic responsibilities for water, fish, wildlife, mineral, land, park, and recreational resources. Indian and Territorial affairs are other major concerns of America's "Department of Natural Resources."

The Department works to assure the wisest choice in managing all our resources so each will make its full contribution to a better United Statesnow and in the future.
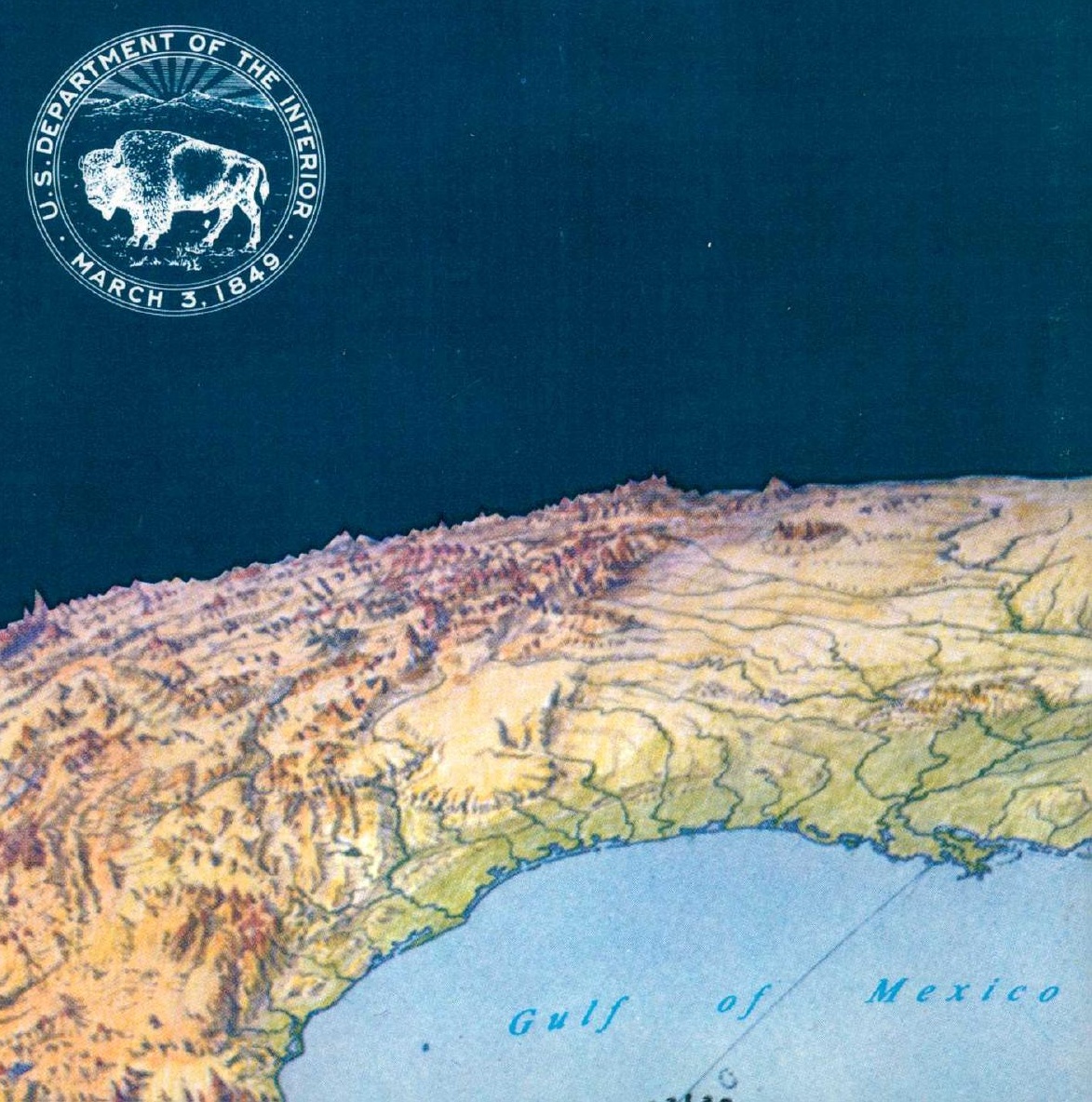